\title{
Nephrotic Syndrome with Lesion of Minimal Change Glomerulonephritis
}

National Cancer Institute

\section{Source}

National Cancer Institute. Nephrotic Syndrome with Lesion of Minimal Change

Glomerulonephritis. NCI Thesaurus. Code C35540.

A renal functional disorder characterized by proteinuria, edema, hyperlipidemia and hypoalbuminemia. It results from damage to the renal vascular filtration apparatus. It is further characterized by an inflammatory reaction in the glomerular capillaries and the effacement of the surrounding epithelial cell foot processes worsening protein leakage. Sequelae may include hypertension, atherosclerosis, infection, hypercoagulablity and renal failure. 